\title{
Dynamic feature analysis to quantity and quality of typical septic tank wastewater
}

\author{
Liquan Lu ${ }^{1, a}$, Liping Qiu ${ }^{1, b^{*}}$, Renzhen Cheng ${ }^{1, c}$, Jiabin Wang ${ }^{1, d}$, Shoubin \\ Zhang ${ }^{1, e}$, Kang Xie ${ }^{1, f}$ and Zeyu Tao ${ }^{2, g}$ \\ ${ }^{1}$ School of Civil Engineering and Architecture, University of Jinan, Jinan 250022, China \\ ${ }^{2}$ School of Municipal and Environmental Engineering, Shandong Jianzhu University, Jinan 250101, \\ China \\ a24lu.liquan@163.com, ${ }^{b}$ lipingqiu@163.com, ${ }^{\mathrm{c} 965510172 @ q q . c o m}$, dcea_zhangsb@ujn.edu.cn, \\ ecea_wangjb@ujn.edu.cn, ${ }^{\mathrm{f}}$ cea_xiek@ujn.edu.cn, ${ }^{\mathrm{g}} \mathrm{zeyutao@sina.cn}$ \\ ${ }^{*}$ Corresponding Author
}

\begin{abstract}
Keywords: two functional areas; septic tank wastewater; wastewater quantity; wastewater quality; monitor and analysis.

Abstract. Water quantity and quality such as COD, ammonia nitrogen and phosphate concentration of two functional areas including residential district and administrative area were obtained through the continuous monitoring and analysis of septic tank effluent's water quality and quantity in administration building and teaching staff dormitory of Jinan University. The results showed that the average concentration of COD, ammonia and phosphate of residential district were $468.02 \mathrm{mg} / \mathrm{L}$, $95.43 \mathrm{mg} / \mathrm{L}, 9.93 \mathrm{mg} / \mathrm{L}$, as well as $204.24 \mathrm{mg} / \mathrm{L}, 41.11 \mathrm{mg} / \mathrm{L}$, and $4.18 \mathrm{mg} / \mathrm{L}$ in administrative area, respectively. The wastewater quantity of residential district was more than that of administrative area, besides some water quality indexes including the concentration, and different functional areas showed obvious change characteristics. Considering the complementation of wastewater quantity of two functional areas in time, the septic tank wastewater of difficult area was advised to treat federatively, in order to regulate the quantity of wastewater, it also can stabilize the quality of wastewater, then provide the feasibility condition of the source control technology.
\end{abstract}

\section{Introduction}

The condition of low carbon nitrogen ratio and low carbon phosphorus ratio in sewage treatment plant was increasing ${ }^{[1]}$, if the removal of nitrogen and phosphorus in the effluent can't reach the standards, it will lead to ecological problems inevitably such as eutrophication and so on ${ }^{[2]}$. In addition to improve the sewage treatment craft and develop efficient treatment technology of wastewater with low carbon to nitrogen ratio as well as low carbon to phosphorus, the wastewater was controlled from source, and causing improvement of influent condition in wastewater treatment plant ${ }^{[3]}$, which was another experimental idea. Septic tank as a temporary and irreplaceable anaerobic structure for treating domestic sewage ${ }^{[4]}$, its effluent has become the key sewage of source control. However, the septic tank effluent is not stable, and the wastewater quantity and quality of different functional areas are different because of the effect of personnel and other uncertain factors, it will be difficult for the use and promotion of source control technology. Therefore, understanding the characteristics of septic tank wastewater quantity and quality on the rational treatment and implementing source control technology are very important.

\section{Sampling monitoring and analysis method}

\section{Brief introduction of function area}

Selecting residential district and administrative area as study object of function area, selected residential building and administration building are 12 high-rise buildings. Each floor of administration building has 14 rooms which can do office work, a male toilet, a female toilet and a wash room. The building has two sewage outfall and sewage is piped to the septic tank. As well as the 
residential including has three units, each unit has two users. The building has full living facilities, and the sewage discharged to the terminal septic tanks.

\section{collection and preservation of wastewater samples}

The spot of flow quantity measurement and collected wastewater samples was arranged in the septic tank outlet of two functional areas. The wastewater quantity was used by simple method of flow stopwatch, measuring cylinder and water samples were collected in accordance with the requirements of water and wastewater monitoring analysis method in China (Fourth Edition) ${ }^{[5]}$. The sampling time ranged from 6 to 22 points, and the wastewater quantity was measured in every $1 \mathrm{~h}$. When the wastewater changed largely, the number of flow measurement was increased at random, and the average value is taken as the hourly quantity.

1.3 Analysis of projects and methods

COD: potassium dichromate method; ammonia nitrogen: sodium reagent spectrophotometric method; phosphate: molybdate spectrophotometric method.

\section{Findings and discussions}

\section{wastewater quantity characteristic analysis}

In the sampling time, the change of wastewater quantity in the septic tank wastewater of two functional area was shown in figure 1.

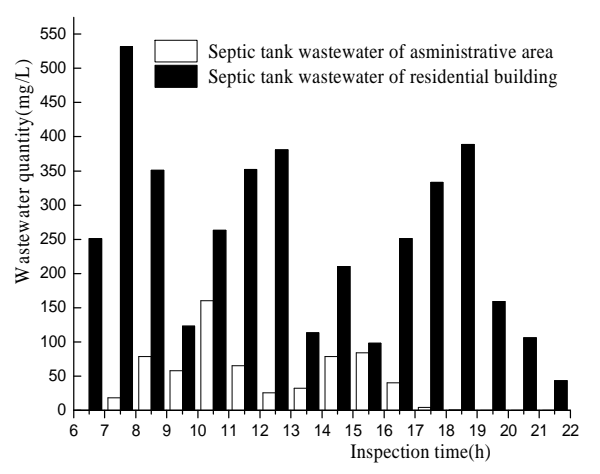

Fig.1 Variation of wastewater quantity of septic tank wastewater with time in different function areas

Which can be seen from Figure 1, the septic tank wastewater of administrative buildings and residential buildings had the characteristics of typical functional areas, which specific performance was as follows: a period of time when residents of residential building get up to the time before going to work was the time quantum of maximum discharge of sewage. Water discharge ranked second was the time at noon and in the evening after work, which was conformed to the rules of basic sewage emission in city ${ }^{[6]}$. While the septic tank sewage of administrative building had obvious sewage discharge characteristics to office area, septic tank sewage emissions was larger at the working time, in especial at 10 to 11 in the morning. The reason was that the business was more and foreign access at this time. And the quantity reduced significantly after working time. With the proposition of same floor of two buildings, compare septic tank wastewater quantity of two functional areas, residential area was more than administrative area, which showed the source of residential area was more extensive than that of administrative area, the source of septic tank wastewater of administrative area was relatively single. Moreover, the water content of the two functional areas presented a complementary trend, which provided favorable stability conditions for the subsequent treatment of integrated wastewater with time.

\section{wastewater quality characteristics analysis}

The study investigated the concentration of $\mathrm{COD}, \mathrm{NH}_{3}-\mathrm{N}$ and phosphate of septic tank wastewater in two functional areas, in the purpose to summarize the typical septic tank wastewater, explore changes rule and laid the foundation for the feasibility study of source control technology. The septic tank wastewater COD changed with hour in each functional area was shown in figure 2. 


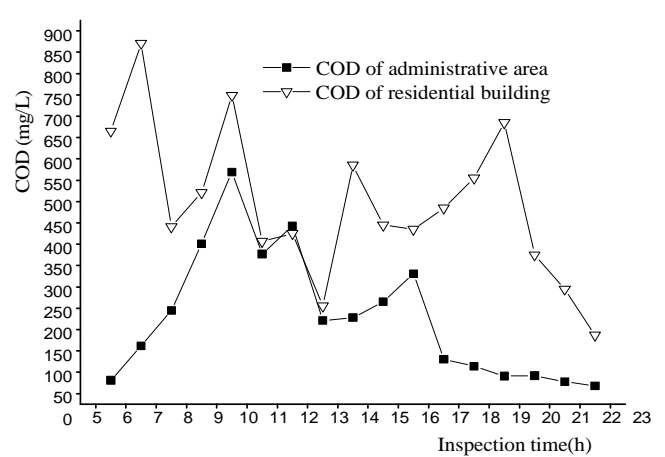

Fig. 2 Variation of COD with time in different functional areas

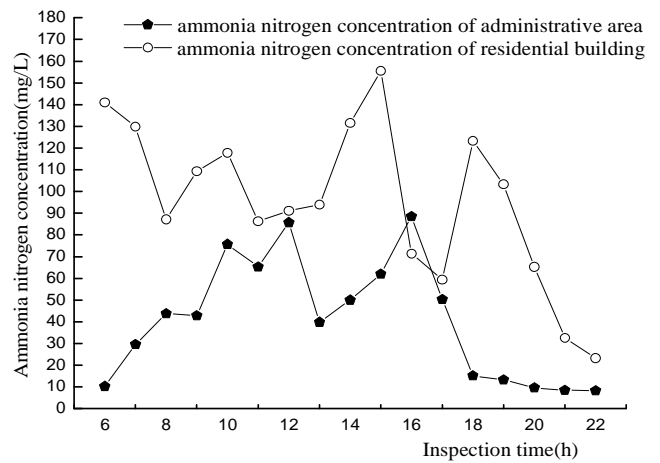

Fig. 3 Variation of concentration of $\mathrm{NH}_{3}-\mathrm{N}$ with time in different functional areas

The monitoring results showed that the COD concentration of septic tank wastewater in residential ranged from 137 to $544 \mathrm{mg} / \mathrm{L}$, the average value was $204.24 \mathrm{mg} / \mathrm{L}$, which changed largely, emergence time of maximum was same to the quantity figure. The value was rise gradually in the working time, and the concentration increase rate of afternoon was greater than the morning. While the COD concentration range of residential septic tank wastewater was $162-846 \mathrm{mg} / \mathrm{L}$, the average value was $468.02 \mathrm{mg} / \mathrm{L}$, the concentration of each time point was more than residential area, so the average concentration was largely more than office area. The maximum value appeared at 7 to 8 in the morning, because this time was the period of working peak and residents had more activities. Moreover, the concentration had the characteristic which it decreased sharply after a small water using peak. It was worth mentioning that the concentration of COD and septic tank wastewater flow has a positive correlation at each time.

The $\mathrm{NH}_{3}-\mathrm{N}$ concentration of septic tank wastewater varies in each functional area with hours as shown in Figure 3. The $\mathrm{NH}_{3}-\mathrm{N}$ concentration of septic tank wastewater in administrative ranged from 25.8 to $85.73 \mathrm{mg} / \mathrm{L}$, the average value was $41.11 \mathrm{mg} / \mathrm{L}$, the maximum period of time was noon 12 to 13 o'clock. The reason may be that emissions wastewater in the morning had anaerobic ammonification and some organic ammonia turned into ammonia. And this part as a supplement, the concentration of ammonia nitrogen in this time was the largest. But also because of this reason, the ammonia was more rise obviously during the afternoon working time. The $\mathrm{NH}_{3}-\mathrm{N}$ concentration range in residential building was $37.6-155.5 \mathrm{mg} / \mathrm{L}$, the average value is $95.43 \mathrm{mg} / \mathrm{L}$, and the coefficient of change was large. The reason was that the anaerobic environment of wastewater was complicated, and the concentration of ammonia nitrogen was unstable. In contrast, the ammonia concentration of two functional areas can be found, the change trend of the two functional areas was roughly the same, but the change of ammonia concentration in administrative area lagged behind, which may be caused by small quantity and concentration.

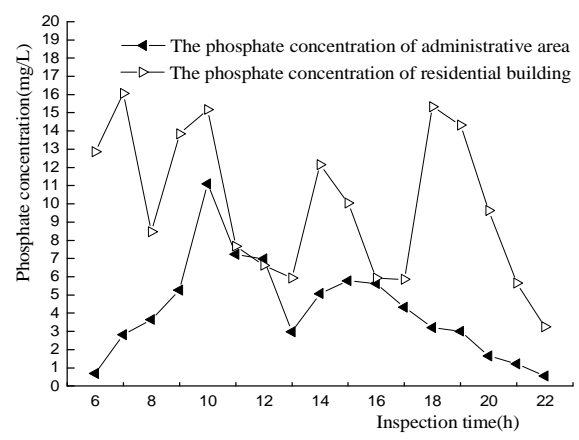

Fig. 4 Variation of phosphate concentration with time in different functional areas

Through investigation, the change of phosphate concentration of septic tank wastewater in each function area was shown in figure 4 . The phosphate concentration range of septic tank wastewater 
discharged from administrative area was $0.55-11.09 \mathrm{mg} / \mathrm{L}$, the average value was $4.18 \mathrm{mg} / \mathrm{L}$. Two numerical peaks were appeared in the morning and afternoon period, phosphorus concentration basically maintained below $10 \mathrm{mg} / \mathrm{L}$, which was a typical low phosphorus wastewater. The concentration of phosphate concentration in residential building was range from 3.26 to $16.06 \mathrm{mg} / \mathrm{L}$, with an average value of $9.93 \mathrm{mg} / \mathrm{L}$, which was slightly higher than the phosphate concentration of septic tank effluent in the administrative area, indicating that there were many sources of phosphate.

Comparing figure 1, figure 2, figure 3 and figure 4 synthetically, this study discovered that the quantity and quality index change trend of each functional area were relatively consistent, indicating that residential area produced more pollutants and its quantity was more, and it provided the more substrates for source control technology. Relative to the residential area, the quantity of administrative building was small. And the quantity of two functional areas was complementary. If the wastewater of the two functional areas can be comprehensive treatment, which can play a role of regulating pool, and the flow rate remained relatively stable, but also add pollutants, improve the recovery rate of nitrogen and phosphorus.

\section{conclusions and recommendations}

Whether quantity of wastewater, or COD, ammonia nitrogen concentration, phosphate and other water quality indicators, residential areas significantly was more than administrative areas, different functional areas showed obvious characteristics of change.

COD, ammonia nitrogen and phosphate concentration of residential area were $468.02 \mathrm{mg} / \mathrm{L}$, $95.43 \mathrm{mg} / \mathrm{L}, 9.93 \mathrm{mg} / \mathrm{L}$, respectively, while which of administrative district were $204.24 \mathrm{mg} / \mathrm{L}$, $41.11 \mathrm{mg} / \mathrm{L}, 4.18 \mathrm{mg} / \mathrm{L}$, respectively. The result showed that the effluent of two functional areas was low phosphorus wastewater with high concentrations of COD and ammonia.

In view of the complementation of wastewater quantity of two functional areas, suggesting that the wastewater of the two functional areas can be comprehensive treatment, which can play a role of regulating pool, and the flow rate remained relatively stable, but also add pollutants, provide feasible conditions for subsequent implementation of source control technology.

\section{Acknowledgements}

This work was financially supported by National Natural Science Foundation of China (51678276), Science and technology development projects of Shandong province (2016GSF117012, 2016CYJS07A03-3).

\section{References}

[1] Yan Zhang, Guodong Ji, Rongjing Wang. Drivers of nitrous oxide accumulation in denitrification biofilters with low carbon: nitrogen ratios[J]. Water Research, 2016, 106, 79-85.

[2] Wei Bi, Yiyong Li, Yongyou Hu. Recovery of phosphorus and nitrogen from alkaline hydrolysis supernatant of excess sludge by magnesium ammonium phosphate[J]. Bioresource Technology, 2014, $166,1-8$.

[3] JA Wilsenach, WP van Bragt, BP De, et al. Evaluation of separate urine collection and treatment to augment existing wastewater treatment works[J]. Water science \& Technology, 2005, 52(4), 71-80.

[4] Christpher D. Cappa, George Tchobanoglous, William R.Horwath, et al. Methane, Carbon Dioxide and Nitrous Oxide Emissious from Septic Tank Systems[J]. Environmental Science \& Technology, 2011, 45, 2741-2747.

[5] State Environmental Protection Administration of China, committee of water and wastewater monitoring and analysis methods. Methods for monitoring and analysis of water and wastewater (Fourth Edition) [M]. Beijing: China Environmental Science Press, 2002.

[6] GB/T 50331-2002, Water consumption standard of urban residents [S]. 